\title{
Digital platforms for urban mobility
}

\section{SIGRADI2018 TECHNOPOLITICAS \\ xxii congresso da sociedade iberoamericana de gráfica digital 22th conference of the iberoamerican society of digital graphics $07|08| 09 \mid$ novembro|2018 iau usp | são carlos | sp br}

\author{
Luísa da Cunha Teixeira \\ LAURD-PROURB-UFRJ | Brazil | luisadacunhateixeira@gmail.com
}

Rodrigo Cury Paraizo

LAURD-PROURB-UFRJ | Brazil | rparaizo@gmail.com

\begin{abstract}
This work aims to analyze the use of digital platforms in urban mobility. It describes examples of applications and platforms grouped by their function, as the way they assist physical displacements in the urban environment. 25 platforms were catalogued in four main categories: mobility orientation, on-demand transport, vehicle sharing and ride-sharing. The use of digital technologies reveals some potentialities and limitations of arrangements, uses and appropriations that deserve to be analyzed in order to understand the possibilities of action facing the challenges posed for urban mobility.
\end{abstract}

Keywords: Urban mobility; Digital platforms; Locative media; Technopolitics.

\section{INTRODUÇÃO}

Este artigo tem como objetivo analisar exemplos de plataformas digitais que atuam em relação à mobilidade urbana, organizando-os em uma categorização de acordo com suas funções no auxílio aos deslocamentos na cidade. Por toda parte, foram sentidos os impactos do planejamento urbano voltado ao automóvel particular, e com poucos investimentos em transporte público - em especial na América Latina.

Desde a metade do século passado, o crescimento urbano no Brasil foi orientado principalmente por uma ótica rodoviarista, e já se fazem sentir, há tempos, os impactos na vida das grandes cidades. Segundo o último relatório da Associação Nacional de Transportes Públicos (ANTP, 2013), a frota de automóveis particulares teve um aumento de mais de $100 \%$ em dez anos (de 2002 a 2012) e passou a representar cerca de $55 \%$ do total de veículos do país.

Os resultados acumulados até então tem influenciado diretamente a qualidade e dinâmica de vida dos cidadãos nos centros urbanos, com engarrafamentos cada vez mais frequentes, que alteram significativamente o tempo das viagens, maior número de acidentes de trânsito, e aumento da poluição atmosférica. O uso das tecnologias digitais revela algumas potencialidades e limitações de arranjos, usos e apropriações que merecem ser analisadas com 0 intuito de compreender as possibilidades de ação frente aos desafios colocados para a mobilidade nas metrópoles.

\section{A QUESTÃO DA MOBILIDADE URBANA DIGITALMENTE ASSISTIDA}

De acordo com Balbim (2016), mobilidade é um termo polissêmico, muitas vezes confundido com termos e conceitos como circulação, transporte, acessibilidade, entre outros; que pode se referir a formas e usos diversos.

No âmbito do planejamento de transportes, o termo mobilidade começa a ser mais utilizado em fins do século XX, com o conceito de Gerenciamento da Mobilidade, que nasce nos EUA na década de 1970 com o objetivo de "racionalizar o uso indiscriminado do automóvel particular e estimular a utilização de formas mais sustentáveis de locomoção" (Balassiano et al., 2005, p. 16).

Diversos autores apontam para uma mudança de paradigma, nos últimos dez anos, no modelo clássico do planejamento de transportes das cidades, quando se passa a observar o problema não mais sob o ponto de vista da oferta, mas sim da demanda (Banister, 2006; Balassiano et al, 2005; Izaga 2009; Amar, 2016).

Segundo Banister (2006), o paradigma da mobilidade sustentável busca entender as dinâmicas de deslocamento nas cidades investigando suas complexidades e estreitando os laços entre uso do solo e transporte. Como uma alternativa à visão até então dominante, a ideia é priorizar o uso do transporte público e o transporte não motorizado, como forma de diminuir a necessidade de uso do automóvel particular.

Amar (2016) ressalta a importância da inovação, tanto tecnológica quanto cultural, para a mudança de paradigma, do modelo clássico do planejamento de transportes para uma visão mais ampla, que vem se 
consolidando na noção de mobilidade urbana. Os avanços tecnológicos vividos nas últimas décadas vêm influenciando o modo de vida do ser urbano, cada vez mais móvel e conectado, configurando o que ele chama de "vida móvel" ("vie mobile", em francês), ou seja, um modo de vida cada vez mais ligado à mobilidade (Amar, 2016, p.13).

As inovações tecnológicas vêm ao encontro dessa nova abordagem sobre a mobilidade, oferecendo novas ferramentas para auxiliar na programação e demanda dos deslocamentos na cidade de forma mais eficiente $e$ sustentável. Cada vez mais, surgem plataformas e sistemas que incentivam o compartilhamento de veículos e viagens, os deslocamentos não motorizados, e uma melhor gestão de transportes públicos, que fortalecem esse novo paradigma.

O conceito de mobilidade aqui analisado se refere aos deslocamentos físicos realizados no espaço urbano, portanto, à mobilidade espacial dentro da cidade. Além disso, o recorte proposto diz respeito à mobilidade de passageiros, deixando de lado toda a logística de transporte e distribuição de produtos e serviços, por exemplo, em que pese sua importância e seu impacto na mobilidade urbana em geral, como foi evidenciado pela recente greve dos caminhoneiros. Finalmente, examinouse essa mobilidade do ponto de vista da interferência dos aplicativos para dispositivos móveis, entendendo que, ainda que incidam sobre práticas muitas vezes preexistentes, eles acabam estimulando uma alteração quantitativa de tal ordem que resulta em mudanças qualitativas no modo de utilizar e encarar a mobilidade urbana.

Essas mudanças são de tal ordem que o próprio conceito de "smart cities/smart urbanism" se alimenta delas. Como afirma Townsend (2014, pos. 57), "smart cities são lugares onde a tecnologia da informação é utilizada para lidar com problemas antigos e novos"; comentando em seguida o grande diferencial representado pelo advento dessas tecnologias para a capacidade de resposta e adaptação quase imediata do transporte de bens e serviços, a partir do sensoriamento remoto e processamento desses dados. Sá (2015), por sua vez, analisa diversos exemplos no campo do urbanismo em geral.

Dada a natureza das próprias cidades como artefatos de concentração de ideias e recursos além de catalisadoras de encontros, não surpreende que os aplicativos tidos como de maior impacto sobre a vida urbana sejam aqueles que interferem na mobilidade, promovendo maior eficiência nos deslocamentos (inclusive para evitar que ocorram, pela telepresença facilitada por diversos aplicativos de mensagem e vídeo).

A eficiência da mobilidade urbana, portanto, não se encontra somente na quantificação de tempos e distâncias, ainda que sejam componentes importantes, mas especialmente na qualidade dos encontros, seja entre pessoas, seja de pessoas com bens, serviços ou mesmo ideias, tanto intencionais quanto aleatórios, promovidos pelos deslocamentos.

\section{PROCEDIMENTOS METODOLÓGICOS}

Aplicativos móveis, os "apps", como ficaram popularmente conhecidos, são softwares desenvolvidos para serem instalados em dispositivos eletrônicos móveis, como smartphones ou tablets, em dois sistemas operacionais principais: Android (Google) e iOS (Apple). Cada um desses sistemas possui uma loja virtual online, onde são disponibilizados os aplicativos. A App Store, da Apple, lançada em 2008, possui atualmente mais de 1 milhão de títulos publicados, divididos em 25 categorias. A Play Store, da Google, antes conhecida como Android Market, possui 3,5 milhões de aplicações disponíveis para download, em 22 categorias.

Buscou-se realizar uma sistematização e classificação de diversos exemplos de plataformas digitais que atuam sobre a mobilidade urbana. Em um primeiro momento, baseando-se na própria classificação dos aplicativos nas lojas online, realizou-se uma busca por aplicativos que explicitamente falassem de transporte de passageiros e orientação no trânsito. A escolha dos exemplos se baseou na experiência pessoal dos pesquisadores, destacando-se plataformas que atuam desde nosso contexto local até exemplos emblemáticos, de abrangência internacional.

$\mathrm{Na}$ App Store, foram encontradas duas categorias pertinentes: "Viagens" e "Navegação". Já na Play Store, foram pesquisados "Mapas e navegação" e "Turismo e local". Não foi possível verificar uma relação direta entre categorias das duas lojas. Apesar da aparente relação entre "Mapas e Navegação" e "Navegação", muitas dos aplicativos classificados como "Mapas e Navegação" na Play Store estão classificados como "Viagens" na App Store. De todos os exemplos analisados, apenas um tem classificação diferente na App Store, o Zumpy, classificado como "Estilo de vida".

No presente trabalho, os aplicativos foram classificados quanto ao ano de lançamento, versão Android e iOS, data da última atualização, local de fundação, abrangência (local, internacional, etc.), presença de GPS, vínculo do condutor, propriedade do veículo, e função na mobilidade.

Verifica-se no campo específico da mobilidade urbana uma multiplicidade enorme e crescente de práticas mediadas por plataformas digitais, e nesse sentido, identifica-se a necessidade de realizar uma pesquisa com esse foco. Como no método enunciado por Sá (2015, p. 28), a ideia é fazer um trabalho de "rastreio e catalogação", registrando diversos exemplos, organizados em categorias, que "ajudem a guiar estudos futuros".

\section{CATEGORIAS DE APLICATIVOS}

Do mesmo modo que os problemas de mobilidade antecedem a tecnologia digital, boa parte de suas soluções também não surgiu com os smartphones. As caronas, as centrais telefônicas de táxis e os serviços de compartilhamento de carros são bons exemplos disso. De fato, muitas vezes, o que se observa com a inserção digital é uma ampliação de sistemas pré-existentes; mas, na escala e resposta imediata permitida pela tecnologia, essas soluções são significativamente ampliadas, a ponto de se tornarem qualitativamente distintas, como atesta o 
próprio caso do Uber, de que trataremos adiante. Mesmo tendo origem em uma prática pré-digital, portanto, as consequências bastante específicas dos meios digitais justificam estudar o fenômeno sob essa ótica.

Foram catalogados até o momento 25 plataformas e aplicativos, agrupados em quatro grandes categorias: orientação de mobilidade, transporte sob demanda, compartilhamento de veículos e compartilhamento de viagens. As categorias propostas classificam os exemplos de acordo com a função que exercem sobre a mobilidade urbana, ou seja, de acordo com a forma que atuam sobre a mobilidade nas cidades, seja mapeando rotas, seja facilitando o planejamento individual da utilização de modais diversos do sistema de transporte público. Dentro dessas grandes categorias podemos perceber também algumas subdivisões.

Dentre as plataformas estudadas, algumas são iniciativas locais, outras ganharam o mercado internacional, passando a atuar em diversas cidades. Podemos dizer que, quanto à abrangência, é conveniente pensar em três tipos de aplicativos: aqueles específicos para cada cidade, aqueles de origem local, mas replicados em outros contextos, e aqueles de aplicação geral (mesmo que iniciados em um contexto menor, mas diretamente escaláveis para áreas mais abrangentes). Nos exemplos estudados, temos características importantes para o entendimento da mobilidade urbana digitalmente assistida.

\section{ORIENTAÇÃO DE MOBILIDADE}

Essa categoria agrupa plataformas e aplicativos que atuam no auxílio à orientação para os deslocamentos na cidade. Portanto, são usadas indistintamente por motoristas a serviço de outros ou pelos próprios indivíduos em deslocamento. Os exemplos mais conhecidos são o Google Maps e o Waze Mobile, ambos presentes em vários países. Como se baseiam no sinal de GPS, que tem abrangência mundial, são frequentemente escalonáveis para corresponder a essa abrangência, dependendo apenas do efetivo mapeamento de ruas. Aplicativos dessa categoria, portanto, ainda que possam ter origem local, se tornam de abrangência internacional rapidamente.

A Waze foi fundada em 2008 em Israel, originalmente chamada de LinQmap, e em 2011 já empregava 80 pessoas. Seu diferencial, se comparada aos sistemas de navegação por GPS tradicionais, vem do fato de se basear em uma comunidade de usuários, aproveitandose da localização fornecida por cada usuário através de seus smartphones, para alimentar seu banco de dados. Foi a primeira plataforma a funcionar desta forma, antes mesmo da Google lançar essa funcionalidade em seu aplicativo de mapas. As informações enviadas pelos usuários possibilitam a atualização da plataforma em tempo real, gerando informações muito precisas sobre o fluxo de tráfego, por exemplo. A comunidade também pode relatar outras informações sobre o trajeto como acidentes, congestionamentos, radares de velocidade, blitzes policiais, etc., e podem atualizar rodovias, pontos de referência e números de casas, compondo um mapa cada vez mais completo e em atualização constante de informações, que são repassadas novamente à comunidade.
Em 2013 a Waze foi comprada pela Google, e seus dados passaram a integrar um banco ainda maior, juntamente com os dados fornecidos pelo aplicativo Google Maps. Criado em 2005, o Google Maps era inicialmente uma plataforma web de mapeamento e navegação em geral, em conjunto com a GoogleEarth, que fornece as imagens de satélite. O serviço se baseia na pesquisa e visualização de mapas, com traçado de rotas e informações cartográficas que foram ficando cada vez mais precisas; atualmente, são fornecidos mapas de mais de 220 países, informações de transporte público de mais de 15.000 cidades.

Com o surgimento dos smartphones com função GPS, a GoogleMaps lançou, em 2008, sua versão móvel para Android e, a partir daí, passou a funcionar também se alimentando das informações de localização de seus usuários, como o Waze. Uma das diferenças entre o Waze e o Google Maps é que este último é uma plataforma de mapeamento e navegação em geral, incluindo opções de diferentes modais, e não só de automóveis particulares. Ele inclui a função do Waze, mas não se restringe a ela. É possível, por exemplo, traçar uma rota a pé, ou de bicicleta, ou inclusive de transporte público, pois ele integra dados das empresas de transportes das principais cidades onde atua.

Daí inferiu-se outra categoria de classificação importante, do ponto de vista da mobilidade urbana: aplicativos uni ou multimodais. O Waze, desse ponto de vista, por ser unimodal - e o modal em questão ser o carro particular -, pode melhorar as escolhas de trajetos dos motoristas, aliviando o tráfego; o Google Maps, ao permitir a visualização de diferentes tempos de deslocamento segundo cada modal (de carro, de ônibus, a pé, de bicicleta ou mesmo de avião, quando o trajeto permite), estimula a exploração dos diferentes modais (mesmo que a combinação de modais seja ainda incipiente), o que pode levar a escolhas mais sustentáveis, em especial para deslocamentos menores.

Outro exemplo a ser analisado é a plataforma da RATP (Régie Autonome des Transports Parisiens), empresa de transporte público de Paris. Nela, é possível ter acesso a todos os mapas de transporte de Paris de forma integrada e dinâmica. A partir das informações de localização de todos os modais de transporte da cidade pode-se traçar itinerários com antecedência. Baseado nos horários de partida e/ou chegada do usuário, o aplicativo calcula a melhor rota, podendo-se escolher pelos modais a serem utilizados, trajeto mais curto, com menos baldeação, entre outras opções. A plataforma integra os sistemas de metrô, ônibus, trens intermunicipais, VLT, e bicicletas públicas compartilhadas (Velib'), sendo possível montar uma enorme quantidade de combinações para realizar os trajetos. O sistema de informações oferecido no aplicativo reflete a grande integração do sistema de transporte de Paris. Essa integração é possibilitada pelo fato da RATP ser a empresa pública gestora de todos os transportes na llede-France, o que possibilita, além da já consolidada eficiência do sistema de transporte público em si, eliminar boa parte, se não toda, da mediação necessária para aquisição dos dados entre diferentes sistemas.

Esse não é o caso de outros aplicativos do tipo, que pretendem ser grandes sistemas integradores de

3 
informação de transportes para qualquer cidade, como é o caso do Moovit ou do City Mapper. Nesses casos, as plataformas dependem das prefeituras ou órgãos gestores e empresas de transporte de cada cidade para conseguir coletar os dados, o que pode prejudicar a eficiência e confiabilidade das informações. O Moovit é o maior aplicativo de transporte público do mundo, com mais de 150 milhões de usuários em 2200 cidades de 80 países. Na cidade do Rio de Janeiro, por exemplo, o Moovit oferece um sistema de informações de diversos modais do transporte público a partir de dados de GPS repassados pelas empresas concessionárias; no entanto, sua usabilidade é bastante questionada pela população carioca, que aponta a falta de precisão dos itinerários. Visando oferecer um sistema mais confiável, a própria Fetranspor lançou, em 2014, o aplicativo Vá de Ônibus (que já existia como plataforma web desde 2007) oferecendo a possibilidade de pesquisar as rotas e horários, além de fornecer a localização via GPS, de todas as linhas de ônibus municipais de seu banco de dados. Mesmo assim, o sistema é ainda pouco preciso com relação à localização dos ônibus em tempo real, além de não apresentar integração com outros modais.

Da mesma forma que o aplicativo RATP reflete a eficiência do sistema de transporte público de Paris, parte das falhas da Moovit ou do Vá de ônibus pode ser atribuída à pouca integração do sistema de transportes como um todo e também às falhas das próprias empresas no controle e monitoramento dos horários e rotas das linhas de ônibus da cidade. A falta de integração entre empresas gestoras de transporte cria dificuldades para, se não impossibilita, a criação de um aplicativo eficiente multimodal como o da RATP - imagine-se compatibilizar diferentes bancos de dados, latências no envio de dados, e políticas de disponibilização dos dados entre as diferentes empresas, para citar apenas algumas das questões envolvidas - e faz com que cada empresa gestora tenha sua própria plataforma (Vá de Ônibus, Metrô Rio, Trens da Supervia, Bike Rio, etc.), de modo que o usuário tem que acessar cada uma delas separadamente.

Essas dificuldades são percebidas, e vem tentando ser superadas no Brasil. Em São Paulo, por exemplo, foi lançado em 2016, o Leve-me: "O Leve-me é um aplicativo de mobilidade urbana gratuito, que facilita a sua vida para se locomover na cidade de São Paulo. Um aplicativo para você, que quer aproveitar o melhor da cidade" (www.leveme.com.br). A plataforma foi desenvolvida pela Ótima, Concessionária de Exploração de Mobiliário Urbano de São Paulo, e permite ao usuário escolher o destino e visualizar as melhores opções de rotas seja de ônibus, metrô, trem, bicicleta ou táxi, podendo optar pela mais rápida, confortável ou saudável. Além das opções de rota, o usuário pode interagir via QR Code ou Realidade Aumentada com campanhas publicitárias veiculadas nos painéis de pontos de ônibus, "participando de promoções, recebendo conteúdos exclusivos, cupons de desconto e até brindes". Conta também com recursos de gamificação, similares ao Waze, onde o usuário acumula pontos para customizar seu avatar e competir num ranking com seus amigos do Facebook que também usam o aplicativo.

Acompanhando ainda mais as novas tendências de mobilidade urbana, foi lançado em 2017 em Berlim o aplicativo Urbi, que integra diversas opções de mobilidade que vêm se consolidando recentemente, como os serviços de mobilidade compartilhada (bicicletas, carros e motos), os serviços de transporte sob demanda (táxis e motorista particular), além dos modais de transporte público.

Percebe-se que os diversos aplicativos de orientação de mobilidade se atualizam para incluir novos modais e novas formas de deslocamento na cidade, visando facilitar a vida do usuário, que cada vez mais se vê diante de novas tendências de mobilidade urbana, como se observa a seguir.

Como mostra o exemplo da integração de transportes, uma smart city passa antes de mais nada por smart policies, ou melhor, por wise politics. Para que um aplicativo integre diferentes sistemas, é benéfico que os criadores e gestores desses sistemas estejam de acordo quanto à própria integração, e aos modos de fazê-la.

\section{TRANSPORTE SOB DEMANDA}

Essa categoria trata de aplicativos de táxi e motorista particular, as chamadas plataformas de e-hailing. Em inglês, a palavra hail denomina 0 ato de se chamar um táxi fazendo um sinal, e no recente contexto das tecnologias digitais emergentes, e-hailing denomina 0 "processo de chamada de um serviço de transporte individual como táxis, carros particulares ou outros veículos, por meio de um dispositivo móvel ou computador" (Gonçalves, 2016).

O crescente avanço dos dispositivos móveis e da tecnologia de GPS permitiu a criação de plataformas que conectam de forma direta e em tempo real passageiros e motoristas. Nesse contexto, diversas empresas surgiram oferecendo inovadores serviços de transporte ondemand. Essas empresas funcionam como plataformas mediadoras, que otimizam a comunicação entre passageiros e prestadores de serviços. Não é preciso possuir uma licença específica - e pública -, como no caso do táxi, para se cadastrar como motorista e, nesse sentido, a falta de regulamentação e de direitos trabalhistas são umas das principais questões levantadas por esse tipo de plataforma.

Uma das empresas mais conhecidas e emblemáticas é a Uber, pioneira e a maior nessa área. Tão inovadora quanto polêmica, a Uber foi a primeira empresa do tipo a oferecer seus serviços no Brasil. Fundada em 2009, em São Francisco, e anunciada inicialmente como aplicativos de caronas, funcionava de fato como um serviço de táxis de luxo, com veículos especialmente selecionados, e com o tempo passou a oferecer as duas opções, de luxo (UberBlack) e normal (UberX). A plataforma expandiu-se rapidamente e hoje está presente em mais de 600 cidades no mundo. Outras plataformas do tipo surgiram, como a Cabify, também presente no Brasil, ou a Lyft, maior concorrente da Uber nos Estados Unidos. A dificuldade de caracterização institucional gera atritos tanto com os concorrentes diretos, os táxis, quando com o poder público, pela taxação; e com seus próprios motoristas, cujas relações trabalhistas com a empresa são pouco claras, dando origem ao próprio termo "uberização" para denotar a precariedade de relações de trabalho. 
Inspiradas pelo crescente sucesso da Uber, surgiram startups visando atuar de forma similar, mas voltados para o mercado de motoristas de táxi, algumas delas cresceram e se destacam por sua abrangência cada vez maior, como é o caso da Easy Taxi, empresa brasileira fundada em 2012 no Rio de Janeiro, presente em mais de 30 países e 420 cidades atualmente. É interessante notar que um dos conceitos originais da empresa é a priorização de mercados com problemas de mobilidade urbana e sistemas de transporte deficientes, constituindo até hoje sua estratégia de expansão, com quase todos os países onde atua sendo de economias emergentes. Outro caso de sucesso é a 99, nascida também no Brasil, que cresceu a ponto de ser comprada por 1 bilhão de reais pelo grupo Didi Chuxing, uma das gigantes chinesas de tecnologia e grande concorrente da Uber. A grande inovação da 99 foi o fato de eventualmente passar a oferecer também o serviço de motorista particular, o "99POP", permitindo que tanto motoristas de táxi licenciados quanto motoristas particulares se registrassem no sistema. Hoje em dia, a 99 conta com 3 categorias: 99taxi, 99pop e o 99top (que se equipara ao UberBlack).

Além desses dois casos, pode-se identificar muitas outras iniciativas difusas, que atuam de forma local, caracterizando a digitalização das centrais telefônicas de táxis em plataformas de e-hailingpróprias de cada cooperativa. Na verdade, muitas dessas plataformas são criadas pelas mesmas empresas de tecnologia, como a Smartsis, que desenvolveu mais de 60 aplicativos de táxi publicados na Play Store. Mais recentemente, a Prefeitura do Rio de Janeiro, através do mesmo órgão responsável pela central de atendimento ao cidadão 1746, lançou a plataforma Taxi Rio, buscando oferecer um sistema mais seguro e moderno ao serviço público de táxi da cidade.

Duas questões principais emergem: a primeira é que, do ponto de vista trabalhista e fiscal, há diversas questões legais criadas a partir da chegada da tecnologia, mas que não são inerentes a ela: é sempre possível legislar em função de mais regulação tanto das relações de trabalho quanto das taxas e impostos incidentes sobre o serviço. $A$ segunda está ligada ao impacto relativo à mobilidade: por um lado, a política de preços praticada (malgrado seu impacto sobre os motoristas) serve como desestímulo para a posse individual de um carro - ou pelo menos à sua utilização diária - o que, se não reduz o número de veículos efetivamente nas ruas (LeBlanc, 2018), ao menos tende a tornar as viagens em si mais eficientes e, potencialmente, a diminuir o ritmo de produção da indústria automotiva.

\section{COMPARTILHAMENTO DE VEÍCULOS}

Essa categoria agrupa plataformas que promovem 0 compartilhamento de veículos como bicicletas e automóveis, dentro do limite de um determinado espaço urbano, com ou sem estações pré-definidas.

Sistemas de bicicletas compartilhadas são atualmente muito comuns nos ambientes urbanos. Mais de 400 cidades no mundo têm seus próprios sistemas e esse número aumenta a cada ano. No entanto, eles não são fruto apenas das inovações tecnológicas e plataformas digitais, sendo o primeiro sistema criado em 1965, em
Amsterdam. O sistema de bicicletas compartilhadas de Rennes, na França, foi o primeiro a usar a tecnologia de cartão inteligente ("smart-card"), em 1998, para possibilitar a liberação das bicicletas nas estações. Em 2001, foi inaugurado o sistema Velo'v de Lyon, no qual se baseou mais tarde o sistema Vélib', de Paris. Ambos se tornaram modelos para os chamados sistemas de terceira geração (ITDP, 2014), em que a tecnologia é usada para identificar e controlar o uso em tempo real, permitindo o monitoramento da capacidade da estação e do número de usuários ativos. No Brasil, a primeira cidade a implementar um sistema do tipo foi o Rio de Janeiro, em 2011, com o BikeRio, expandido para outras cidades a partir de 2013. Atualmente o Rio de Janeiro possui 2.600 bicicletas disponibilizadas em 260 estações pela cidade.

Mais recentemente, startups chinesas lançaram plataformas de compartilhamento de bicicletas sem estações (em inglês, dockless bike-share systems), em que as bicicletas possuem trancas individuais e podem ser estacionadas livremente pela cidade, ficando independentes das estações. Todo o processo, desde a busca da bicicleta mais próxima até o pagamento, é feito através dos smartphones, que destravam as bicicletas com a leitura de um QR-code. A Ofo, primeira plataforma desse tipo, foi fundada em 2014, seguida pela Mobike, em 2015, ambas com sede em Pequim. A Limebike, de 2017, é a versão estadunidense, com sede na Califórnia.

O compartilhamento de automóveis ou "carsharing", em inglês, é uma opção que permite utilizar o transporte individual de forma mais racional, usando o carro apenas quando realmente é necessário, muitas vezes como um complemento a outros transportes como a bicicleta, o ônibus e o metrô. Bem menos comuns, se comparados aos de bicicletas, eles também estão presentes em diversas cidades do mundo. Na mesma lógica do Velib', Paris inaugurou, 10 anos depois, o sistema de compartilhamento de carros elétricos denominado Autolib'.

Outra iniciativa similar ao Autolib' é o Car2Go, que visa o compartilhamento de veículos particulares, com a diferença de que estes não são elétricos. Essa diferença libera os carros do sistema de estações pré-definidas, permitindo aos usuários estacioná-los em qualquer vaga normal dentro de um perímetro limite na cidade. $E$, da mesma forma, buscar os veículos mais próximos da sua localização, a partir do GPS de cada carro do sistema. No Car2Go a localização dos veículos, e todo o processo de reserva, abertura da porta, ignição do motor e pagamento é feito por meio da plataforma móvel. Já no Autolib, pode ser emitido um cartão pré-pago que realiza essas funções. A Car2Go é a maior empresa de compartilhamento de carro do mundo, nascida em UIm, na Alemanha e já está presente em mais de 26 cidades na Europa, América do Norte e Ásia.

Uma nova tendência identificada nessa categoria são plataformas que misturam as vantagens do Car2Go, com a ideia de utilizar carros elétricos, preconizada pela Autolib'. Esse é o caso da Share'nGo, startup italiana fundada em Milão em 2016, que disponibiliza carros elétricos nas regiões de Milão, Florença, Roma e Módena, e também da Emov, lançada em Madrid em 2017. Nesses sistemas os carros elétricos não precisam de estações para serem recarregados, podendo ser

5 
estacionados livremente dentro de um determinado perímetro.

No meio termo entre os sistemas de compartilhamento de bicicletas e de carros elétricos, está o compartilhamento de motos elétricas, como o Mimoto, fundada em Milão.

Apesar dos aplicativos terem sido agrupados na mesma categoria, na verdade, ao se examinar possíveis efeitos, é preciso considerar o tipo de modal envolvido. No caso das bicicletas, pode-se inferir um estímulo ao uso da bicicleta não apenas porque o sistema dispensa a propriedade de uma, mas porque o sistema de estações acaba permitindo uma combinação eficiente da bicicleta com trechos a pé e de metrô, liberando o usuário da necessidade de estacionar a bicicleta ou de transportá-la em trens, o que nem sempre é simples.

No que se refere aos carros, a questão da posse envolve tanto uma indústria quanto políticas de desenvolvimento econômico que seriam bastante afetadas por uma mudança cultural dessa ordem, já que a própria estrutura do negócio se alteraria - ainda que não necessariamente com menos número de viagens ou com aproveitamento mais eficiente dos veículos, já que o compartilhamento de veículos não necessariamente significa o compartilhamento das viagens em si.

\section{COMPARTILHAMENTO DE VIAGENS}

Essa categoria agrupa plataformas que promovem 0 compartilhamento de viagens, normalmente em carros particulares, promovendo uma ocupação mais eficiente. Em inglês ridesharing, ou em francês covoiturage, no Brasil é comumente conhecido pelo termo "carona". O ato de compartilhar uma viagem ocupando lugares vagos é muito anterior ao aparecimento das tecnologias de informação e comunicação digitais, sendo uma prática de colaboração e compartilhamento antiga, presente em diversas sociedades. A análise divide-se entre viagens de longa distância, realizadas entre duas cidades de forma intermunicipal, e as de curta distância, realizadas dentro de uma cidade, de forma intra-urbana.

Uma das plataformas mais conhecidas atualmente é a BlaBlaCar, que visa o compartilhamento de viagens de longa distância, ocupando as vagas ociosas em automóveis particulares. Nascida na França, em 2004, inicialmente como uma plataforma web de viagens compartilhadas chamada covoiturage.fr, criada por Vincent Caron e comprada em 2006 por Frédéric Mazzella. Inicialmente o sistema se baseava em uma página na internet onde eram anunciadas as vagas ociosas para viagens de carro entre cidades na França, e os passageiros interessados podiam buscar no website por essas vagas e reservá-las, sem nenhum custo além da divisão das despesas, acordada entre o motorista e os viajantes. Plataformas do mesmo tipo existiam em outros países na Europa, como Portugal (boleias.pt), Alemanha (mitfahrgelegenheit.de), Espanha, Itália, Reino Unido, entre outros. Com o aumento cada vez maior do uso da plataforma na França, ela começa a se expandir para outros países, comprando as plataformas concorrentes. Em 2013, a plataforma é renomeada de BlaBlaCar e continua a se expandir, inclusive para fora do continente europeu. Atualmente, é a maior empresa de compartilhamento de viagens de longa distância do mundo. Mais recentemente, implementou em seus mercados na Europa o pagamento online, através de cartão de crédito, com isso passou a cobrar uma taxa sobre cada reserva, conquistando um maior rendimento.

No Brasil, existiu a plataforma Tripda, de 2014 até 2016, quando teve suas atividades descontinuadas pelo elevado custo de manutenção e falta de retorno financeiro.

A ideia de compartilhar viagens, ocupando vagas ociosas em carros particulares, não se restringe a viagens de longa distância. Viagens de curta distância, dentro de uma mesma cidade ou região metropolitana são um nicho muito promissor, e ainda pouco explorado. A maior dificuldade na organização de uma plataforma como o BlaBlaCar, para viagens curtas dentro da cidade é a falta de definição clara de pontos de origem e destino, já que os deslocamentos intra-urbanos são muito mais dispersos, ou seja, não há a definição de uma cidade origem para uma cidade de destino. Já houve no Brasil algumas tentativas de criar esse tipo de plataforma, como o Minha Carona (criada por Guilherme Pim, em 2014, no Rio de Janeiro), mas que não teve continuidade. Algumas iniciativas trabalham com a noção de "polos geradores de viagens" (Silva et al., 2016), e assim conseguem organizar as caronas para um determinado ponto concentrador. Polos geradores de viagens são locais que concentram grande quantidade de deslocamentos pendulares, normalmente instituições de ensino, grandes empresas, estádios, hospitais, entre outros. Nesse sentido, identifica-se algumas plataformas como por exemplo o Zimride, uma das maiores plataformas de viagens compartilhadas dos Estados Unidos, criada em 2007. O Zimride tem como nicho principal os campi universitários, grandes polos geradores de viagens, estando presente em mais de 125 campi por todo o país. Interessante pontuar que, de todas as plataformas estudadas, a Zimride é a única que até hoje não possui aplicativos para celular, atuando somente por meio da plataforma web.

No Brasil, iniciativas semelhantes vêm sendo testadas nos últimos tempos. A dificuldade de acesso aos campi universitários (pela precariedade de transporte público, ou a falta de integração com a cidade), além da predominância da ótica rodoviarista na maior parte dos centros urbanos, faz com que muitas pessoas utilizem carros particulares para ir e voltar das universidades. Com isso, surge também, naturalmente, a vontade das pessoas em se organizar para realizar essas viagens de forma compartilhada. Com o advento das redes sociais e o avanço das tecnologias de informação e comunicação, essa organização é facilitada e rapidamente toma grandes proporções. Percebendo esse movimento, algumas iniciativas surgem na forma de plataformas digitais, inicialmente restritas à web, como o Caronetas, criado em 2011. No entanto, essas plataformas não funcionaram por muito tempo. Com a popularização das plataformas para dispositivos móveis, e dos serviços baseados em localização (De Souza e Silva, 2013), plataformas restritas à web tem cada vez menos alcance de usuários, pedindo uma atualização para esse tipo de tecnologia. Em 2016, foi lançado na Universidade Federal do Rio de Janeiro o aplicativo Caronaê, para iOS e Android, permitindo o compartilhamento de viagens de ida e volta dos campi. Com mais de 13.000 usuários, o 
sistema tem código-fonte aberto e a intenção de ser replicado em outras instituições de ensino pelo país, consolidando cada vez mais a cultura das caronas e o compartilhamento de viagens. Além de trabalhar com a noção de "polo concentrador de viagem", o diferencial do Caronaê é o uso exclusivo pela comunidade acadêmica das universidades, vinculado ao sistema de cadastro e autenticação das mesmas. Recentemente, em 2018, a plataforma Wunder, nascida na Alemanha, chega ao Rio de Janeiro, oferecendo um sistema de caronas intraurbanas. No entanto, não possui um controle consistente da comunidade participante, sendo aberto a toda a população da cidade, o que, num primeiro momento, traz certa desconfiança, pois não resolve a questão da segurança nas viagens.

O compartilhamento de viagens, em especial no caso do automóvel, traz o benefício da utilização mais eficiente do modal (mais passageiros por carro), com eventual diminuição de automóveis nas ruas (nos casos em que um proprietário de automóvel opta por pegar carona); por outro lado, ao forçar a convivência entre duas pessoas, muitas vezes desconhecidas (e o cadastro no sistema serve como mecanismo de proteção para os envolvidos), a prática pode estimular justamente o tipo de encontro casual vital para as cidades.

\section{DISCUSSÃO}

As facilidades e simplicidades de acesso, possibilitadas pela internet e inovações tecnológicas, trazem novas dinâmicas de consumo e de trabalho, ainda pouco estudadas, e que se revelam cada vez mais complexas. À sombra dessa facilidade, consolidam-se muitas vezes processos de precarização das condições de trabalho, sem regulamentação mínima, que aumentam os rendimentos daqueles que possuem as plataformas. A ideia de "colaboração" e "compartilhamento" são então deturpadas, e usadas numa lógica mercadológica que "confunde quem legisla, quem trabalha e quem consome" (Rusche \& Santini, 2016).

A Uber é a plataforma que mais levanta a polêmica sobre essas novas relações, pelas diversas denúncias que vão desde a adoção de estratégias por parte da empresa para aumentar a eficiência dos motoristas, diminuindo os custos trabalhistas, até relações sociais e de trabalho extremamente complexas (Firmino \& Cardoso, 2018).

O fenômeno conhecido como "uberização" é marcado, principalmente, pela precarização das relações de trabalho, já que as empresas, proprietárias do sistema de tecnologia, se apresentam como mediadoras entre trabalhadores autônomos e os consumidores do serviço, extraindo o máximo de valor dessa mediação. Segundo Scholz, essa é a lógica da economia do compartilhamento no que ele chama de "capitalismo de plataforma" (2016, p.21). Uma eficiência no compartilhamento construída com base na "extração de valor para investidores e proprietários" (Scholz, 2016, p.36).

O compartilhar, para além da "economia do compartilhamento", tem um importante valor no novo paradigma da mobilidade sustentável. Como se observa explicitamente no nome de duas das categorias aqui elaboradas e nas plataformas nelas estudadas, o compartilhamento é um dos grandes potenciais de racionalização do uso do automóvel particular, tornando mais eficiente tanto as vagas ociosas em viagens quanto o próprio número de carros por pessoas. Além disso, contribui para reduzir custos, aumentar o sentimento de parcerias e do uso comunitário de bens e serviços e aproximar pessoas. A crítica à "economia do compartilhamento" não se dá no sentido de desqualificar as novas relações fundamentadas na confiança entre as pessoas, ou o uso racional de objetos e recursos ambientais, mas de chamar a atenção para os caminhos pelos quais chegamos a esse compartilhamento.

Os sistemas de compartilhamento de bicicletas, por exemplo, também têm um papel importante para a mobilidade urbana, no sentido da sustentabilidade, incentivando uma alternativa não motorizada de transporte. Do ponto de vista da mobilidade urbana, pode-se perceber que as inovações tecnológicas, tendem a ir na direção do novo paradigma da mobilidade, incentivando alternativas mais sustentáveis e formas de reduzir os problemas gerados pelo uso indiscriminado do carro.

\section{CONSIDERAÇÕES FINAIS}

A elaboração de uma taxonomia das plataformas digitais de mobilidade urbana permitiu a observação de um panorama geral das novas tendências trazidas pelos dispositivos tecnológicos, mas também a análise de suas especificidades, e da forma como cada uma atua no ambiente urbano. Reunir plataformas em grupos de acordo com a função permitiu identificar essas grandes tendências, mas a análise dos exemplos demonstrou as pequenas diferenças entre elas.

Pode-se dizer que para todas categorias propostas já existiam soluções "analógicas", mas que ressurgiram ou foram ampliadas pelo uso das tecnologias digitais. Sistemas de táxi, caronas e mesmo sistemas de bicicletas e carros compartilhados, não são consequência da emergência das plataformas digitais, no entanto, esses sistemas vêm sendo ampliados consideravelmente e atualizados a cada momento com as novas tecnologias.

Não se pretende neste trabalho esgotar as análises sobre os exemplos, muito menos limitar o contexto das plataformas digitais de mobilidade aos exemplos aqui categorizados. Pelo contrário, a ideia é explorar as categorias de forma a entender os modos de funcionamento essenciais desses aplicativos, ajudando a criar ferramentas de exploração conceitual de novas possibilidades; e criar uma base que possa continuar sendo alimentada, pois a cada momento surgem novas plataformas explorando as possibilidades de mobilidade urbana e que podem ter funções inusitadas e ainda não categorizadas. Nesse sentido, esse trabalho é também uma forma importante de registro, já que, da mesma forma que a cada momento surgem novas plataformas, também muitas delas podem ser desativadas ou descontinuadas.

\section{AGRADECIMENTOS}

Os autores gostariam de agradecer aos colegas, orientandos, pesquisadores e alunos de graduação do Laboratório de Análise Urbana e Representação Digital 
do Programa de Pós-Graduação em Urbanismo da FAUUFRJ, assim como ao CNPq, pelo auxílio no desenvolvimento deste trabalho como parte da pesquisa de mestrado em Urbanismo desenvolvida no PROURB.

\section{REFERÊNCIAS}

Amar, G. (2016). Homo mobilis. Une civilization du mouvement. Paris: FYP Editions.

Associação Nacional de Transportes Públicos - ANTP. (2015). Sistema de Informações da Mobilidade Urbana - Relatório Geral 2013. Brasília.

Balassiano, R.; Santos, M. P. S.; Andrade, A. R. (2005). Gerenciamento da Mobilidade: Princípios para a sua Aplicação com Base Na Informação. Revista CETRAMA, Salvador, v. 2, n.2.

Balbim, R. (2016). Mobilidade: uma abordagem sistêmica. In: R. Balbim, C. Krause \& C. C. Linke (Eds.). Cidade e Movimento: mobilidades e interações no desenvolvimento urbano. Brasília: Ipea, ITDP.

Banister, D. (2008). The sustainable mobility paradigm. Transport Policy, 15, 73-80.

De Souza e Silva, A. (2013). Location-aware mobile technologies: Historical, social and spatial approaches. Mobile Media \& Communication - SAGE Publications, v. 116, p. 07.

Gonçalves, C. L. R. (2016). As plataformas de e-hailing presentes no ecossistema de mobilidade urbana no Brasil: um estudo de múltiplos casos. Dissertação de Mestrado. Rio de Janeiro: COPPEAD-UFRJ.

Instituto de Políticas de Transporte e Desenvolvimento - ITDP. (2014). Guia de Planejamento de Sistemas de Bicicletas Compartilhadas. Rio de Janeiro: ITDP.
Izaga, F. (2009). Mobilidade e Centralidade no Rio de Janeiro". Tese de Doutorado. Rio de Janeiro: PROURB-UFRJ.

LeBlanc, S. (2018, Feb. 25). Studies are increasingly clear: Uber, Lyft congest cities. APNews. Retrieved from https://apnews.com/e47ebfaa1b184130984e2f3501bd125d

Ministério das Cidades. (2012). Política Nacional de Mobilidade Urbana. Brasília: Ministério das Cidades. Retrived from http://www.portalfederativo.gov.br/noticias/destaques/municip ios-devem-implantar-planos-locais-de-mobilidadeurbana/CartilhaLei12587site.pdf

Rocha, I. A.; Meyer, M.; Balassiano, M.; Balassiano, R. (2016). Caronaê UFRJ - unificando e ampliando as caronas na Cidade Universitária/UFRJ. In: XIII Encontro Nacional de Engenharia e Desenvolvimento Social (ENEDS) Florianópolis.

Rusche, A; Santini, D. (2016) Plataformas de Solidariedade. In: T. Scholz. Cooperativismo de Plataforma. São Paulo: Fundação Rosa Luxemburgo; Editora Elefante; Autonomia Literária.

Sá, A. I. J. A. (2015). Urbanismo Entre Pares: Cidade e Tecnopolítica. Dissertação de Mestrado. Belo Horizonte, NPGAU-UFMG..

Scheiber, N. (2017, April 02). How Uber Uses Psychological Tricks to Push Its Drivers' Buttons. The New York Times.

Scholz, T. (2016). Cooperativismo de Plataforma. São Paulo: Fundação Rosa Luxemburgo; Editora Elefante; Autonomia Literária.

Silva, R. C.; Portugal, L. S.; Balassiano, R. (2016). Sistema De Carona Solidária Como Estratégia De Gerenciamento Da Mobilidade em Campi Universitários. In: XIV Rio de Transportes (pp. 1-12). Rio de Janeiro: PET - COPPE.

Townsend, A. M. (2014). Smart Cities: Big Data, Civic Hackers, and the Quest for a New Utopia. (1st ed.) New York: W. W. Norton \& Company. 